\title{
Laser trabeculoplasty as supplementary treatment for primary open angle glaucoma
}

\author{
MARK B SHERWOOD, JOHN LATTIMER, AND ROGER A HITCHINGS \\ From Moorfields Eye Hospital, High Holborn, London WC1V $2 A N$
}

SUMMARY A prospective trial was conducted of laser trabeculoplasty randomly assigned to one eye of a group of elderly patients with bilateral primary phakic open angle glaucoma who were already taking the maximum medical treatment that they could tolerate. With a minimum followup of $2 \frac{1}{2}$ years (mean 35 months) a significant fall in mean intraocular pressure of over $7 \mathrm{mmHg}$ $(30 \%)$ at the time of the patient's last visit was noted in the treated eye.

Surgery and medical therapy have been employed since the 19th century to lower intraocular pressure in patients with glaucoma, but in the past few years argon laser therapy has gradually been gaining acceptance as a new method of treatment either to supplement or to replace these options.

Initially in the early 1970 s a high intensity laser beam was used to perforate the trabecular meshwork and enter the canal of Schlemm.' This approach achieved only a temporary pressure reduction because of the healing of the micropuncture sites. It was subsequently found that extensive laser application to the anterior chamber angle in monkeys could actually induce glaucoma. ${ }^{2}$ In 1979, however, a different approach was proposed. ${ }^{34}$ By using the argon laser with a far lower power setting so as to induce contraction rather than puncture of the collagen in the trabecular meshwork, a much longerlasting reduction of intraocular pressure was achieved. Following this ${ }^{3}$ and other ${ }^{5-7}$ encouraging reports from the USA a prospective trial was set up at the Glaucoma Unit, Moorfields Eye Hospital, to investigate the effects of laser trabeculoplasty in a discrete, but clinically the most common, groupnamely, elderly patients with primary chronic open angle glaucoma.

\section{Patients and methods}

A highly defined group of elderly patients was selected according to the following criteria:

(a) Bilateral primary open angle (simple) glaucoma as judged by elevation of intraocular

Correspondence to R A Hitchings, FRCS. pressure (above $21 \mathrm{mmHg}$ ), glaucomatous disc change, and visual field loss.

(b) No previous eye surgery nor evidence of other eye disease.

(c) Patients already taking in both eyes the maximum antiglaucoma medication that could be tolerated (Fig. 1). In most cases this would have been a minimum of two and a maximum of four antiglaucoma medicines (timolol, pilocarpine, sympathomimetics, and acetazolamide in varying combinations). Yet despite this treatment the intraocular pressure was consistently exceeding $21 \mathrm{mmHg}$ and considered to be inadequately controlled.

Before laser treatment was given a baseline ophthalmological examination was performed and full history recorded. The initial intraocular

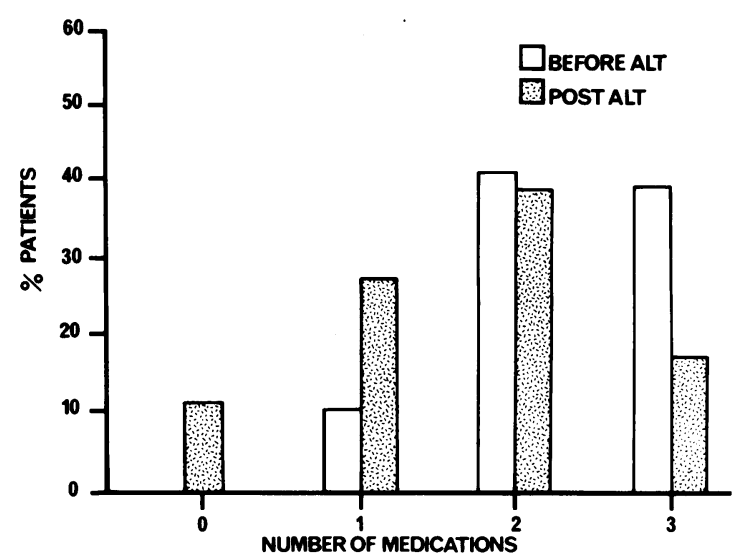

Fig. 1 Reduction in medication after laser treatment. $A L T=$ argon laser treatment. 
pressure' in each eye, by means of a Goldmann applanation tonometer, was taken as the average pressure of the last three clinic visits. One eye was then randomly selected by computer for laser therapy, the other eye acting as a control.

The laser trabeculoplasty consisted of a single outpatient sitting at which 100 evenly spaced, low intensity burns 0.1 second duration were applied with a continuous wave argon laser (Laser Tek) and Goldmann three-mirror contact lens, to the $360^{\circ}$ of the midtrabecular meshwork. ${ }^{8}$

In the first six patients a spot size of $350 \mu \mathrm{m}$ was chosen; and for the remainder $150 \mu \mathrm{m}$ was employed because of difficulties in focusing the larger $350 \mu \mathrm{m}$ spot. The power was adjusted for each individual to give an endpoint of blanching and minimal vaporisation bubbling. It was found that a power setting of 0.5 to 1 watt was usually sufficient.

After laser treatment the previous maximum tolerated medical therapy was continued to both eyes and, in addition to the treated eye only, prednisolone drops $0.1 \%$ qid were added for about one week. The patients were reviewed on a regular basis, initially at frequent intervals and then later every three months. Nearly all the postlaser tonometry readings were checked by two independent observers, one of whom was a glaucoma technician who had no knowledge of which eye had received the argon laser trabeculoplasty. The glaucoma visual fields were also assessed by two observers, one of whom was the senior glaucoma field technician, and who again was unaware of the patient's past laser history.
It was decided at the outset of the trial that, if the laser treatment produced a persistent lowering of IOP lasting for one year, the same treatment would be offered to the 'untreated' eye. At the same time an attempt would be made to withdraw some or all of the antiglaucoma treatment given to the 'treated eye'.

\section{Results}

Twenty-five patients were initially included in the study; their mean age was 72.5 years at the start (range 56 to 90). Of these, one died six months after laser treatment and was excluded, though his intraocular pressure had fallen from a baseline of 22 $\mathrm{mmHg}$ to $16 \mathrm{mmHg}$ at his last reading. The 24 surviving patients had a minimum follow-up of $2 \frac{1}{2}$ years (range 30 to 40 months, mean 35 months). One patient was committed to an institution with senile dementia and his condition was such that it was impossible to obtain accurate visual fields, though his intraocular pressures have been followed up.

Before laser trabeculoplasty the mean intraocular pressures on treatment were similar in the laser treated and untreated eyes $(23.8 \mathrm{mmHg})$. After laser treatment there was, by one month, a significant fall in the mean pressure in the treated eye which has largely been maintained. A transient initial fall in the untreated eye was also seen (Table 1, Fig. 2).

After one year attempts were made to reduce the medication as far as possible in the treated eye while still maintaining adequate control of the glaucoma. Three of the 24 surviving patients (13\%) were able to

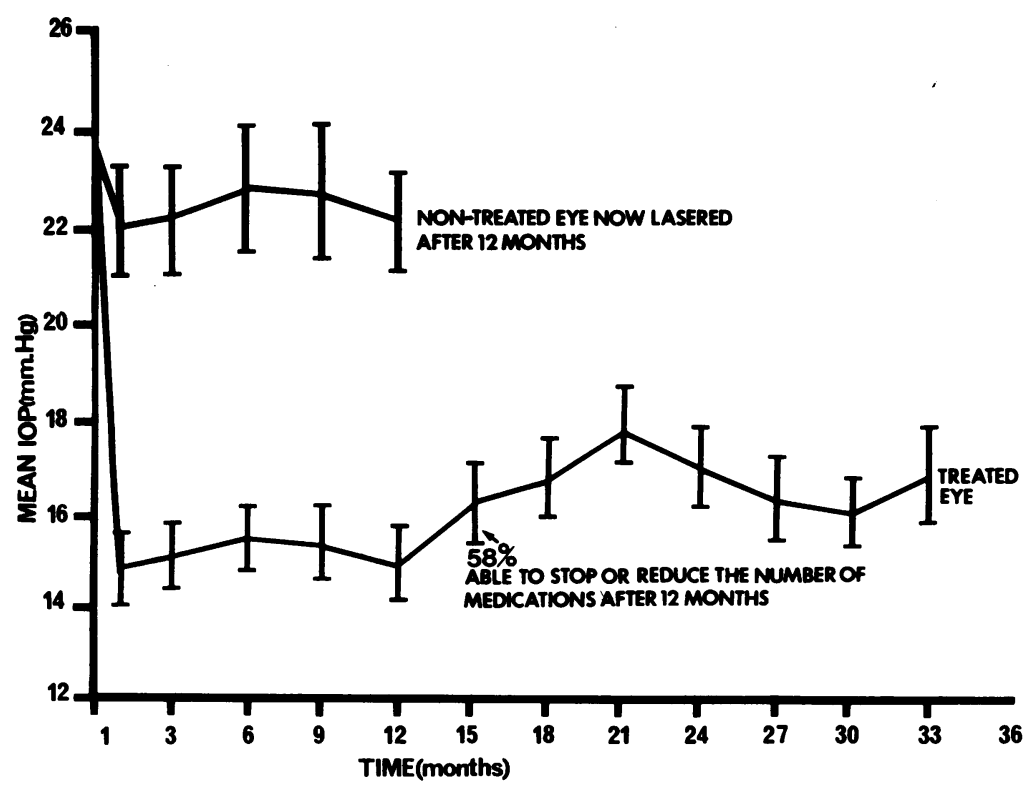

Fig. 2 Intraocular pressure changes plotted against time in patients receiving laser trabeculoplasty compared with those not receiving laser trabeculoplasty for the first one year of the Study. 
Table 1 Comparison of intraocular pressure in patients after laser trabeculoplasty to one eye

\begin{tabular}{|c|c|c|c|c|c|}
\hline Time (months) & No. of patients & $\begin{array}{l}\text { Lasered eye mean } \\
\text { intraocular pressure } \\
(\mathrm{mmHg})\end{array}$ & $\begin{array}{l}\text { Non-lasered eye mean } \\
\text { intraocular pressure } \\
(\mathrm{mmHg})\end{array}$ & $\begin{array}{l}\text { Comparison of mean } \\
\text { intraocular pressure non- } \\
\text { lasered to lasered eye }\end{array}$ & pValue \\
\hline Baseline & 24 & $23 \cdot 8$ & $23 \cdot 8$ & 0 & - \\
\hline 1 & 24 & 14.9 & $22 \cdot 0$ & $7 \cdot 1$ & $<0.001$ \\
\hline 3 & 24 & $15 \cdot 1$ & $22 \cdot 2$ & $7 \cdot 1$ & $<0.001$ \\
\hline 6 & 24 & $15 \cdot 5$ & $22 \cdot 8$ & $7 \cdot 3$ & $<0.001$ \\
\hline 9 & 24 & $15 \cdot 4$ & $22 \cdot 7$ & $7 \cdot 3$ & $<0.001$ \\
\hline 12 & $23^{*}$ & $15 \cdot 0$ & $22 \cdot 1$ & $7 \cdot 1$ & $<0.001$ \\
\hline 15 & $23^{*}$ & $16 \cdot 3$ & & & \\
\hline 18 & $23 \dagger$ & $16 \cdot 7$ & & & \\
\hline 21 & 24 & $17 \cdot 8$ & & & \\
\hline 24 & 24 & $17 \cdot 0$ & & & \\
\hline 27 & 24 & $16 \cdot 3$ & & & \\
\hline 30 & $23 \ddagger$ & $16 \cdot 0$ & & & \\
\hline 33 & 17 & $16 \cdot 8$ & & & \\
\hline 36 & 8 & $18 \cdot 6$ & & & \\
\hline
\end{tabular}

* One patient with irregular follow-up at this time.

†Irregular follow-up at this stage in patient institutionalised with senile dementia

$\ddagger$ One patient underwent trabeculectomy surgery at 27 months after argon laser trabeculoplasty.

stop all treatment, while a further $11(46 \%)$ came off some of their medications. One patient, who was a poor complier, had acetazolamide tablets added to his baseline eyedrop regimen. The mean number of different antiglaucoma medications taken before laser treatment was 2.3 per patient and at their last visit 1.6 per patient (Fig. 1).

Nineteen of the $23(83 \%)$ patients in whom it has been possible to obtain Goldmann visual field analyses have maintained stable visual fields. Of the remaining four cases two have shown slight field progression despite intraocular pressures constantly recorded below $21 \mathrm{mmHg}$ (mean intraocular pressure $12 \mathrm{mmHg}$ and $18 \mathrm{mmHg}$ respectively). However, these findings did not differ significantly from the visual field changes seen in the control eye.

If success of laser treatment is defined in intraocular pressure terms as $(a)$ a fall of intraocular pressure of at least $20 \%$ from baseline (mean of last three readings) and in addition (b) no intraocular pressure readings above $21 \mathrm{mmHg}$, then treatment in 19 of the 24 patients $(79 \%)$ was a success with a minimum follow-up of $2 \frac{1}{2}$ years. Of the five failures by the above criteria three failed after one year ('late failures'), and one of these required filtration surgery at 27 months after argon laser trabeculoplasty.

\section{Discussion}

Argon laser trabeculoplasty was able to produce a clinically useful fall in intraocular pressure of more than $7 \mathrm{mmHg}(30 \%)$ in this group of elderly patients with chronic simple glaucoma who were already taking the maximum medical therapy that they could tolerate. In over $80 \%$ of patients no further loss of visual field has occurred so far, though this did not differ significantly from the control group. (It has to be remembered that the intraocular pressures in these control eyes remained in excess of $21 \mathrm{mmHg}$ only for the first 12 months of the study, after which time these eyes too would have been treated with laser trabeculoplasty.)

The eyes treated in this study received laser energy to $360^{\circ}$ of the trabecular meshwork at one time. More recent work has shown that this treatment could result in a temporary increase of intraocular pressure. ${ }^{9}$ We now give the same $360^{\circ}$ treatment in two separate sessions, treating one half of the trabecular meshwork each time, and immediately after each session instil pilocarpine in an attempt to minimise any transient ocular hypertension.

Wise and Witter's original description recommended the use of a spot size of $50 \mu \mathrm{m} .{ }^{3}$ In-vitro studies suggest that a larger spot size may be more efficacious. ${ }^{10} \mathrm{~A}$ clinical study comparing the use of different spot sizes supports this view (Lattimer and Hitchings, in preparation). The results obtained by our technique using $150 \mu \mathrm{m}$ spots size certainly compare well with those obtained by others. ${ }^{5-7}$

During the first year of the study the intraocular pressures in the 'control' group showed a marked fall over the first one to two months (Fig. 2). We considered that this was a placebo effect, for the intraocular pressures in this group then rose to the prestudy levels without any alterations in medication having taken place. We consider that this response highlights the importance of restricting the number of variables in a prospective clinical study. After one year of follow-up, as Fig. 2 shows, a steady state in intraocular pressure levels had been reached. Thus it 
was considered reasonable not only to treat the control group with laser but also to try to withdraw antiglaucoma medicines from the treated group.

. The good results of laser trabeculoplasty in patients who are already on a full medical regimen led to the idea of using the laser earlier in the disease process and indeed as the primary treatment of certain types of glaucoma. Studies are already under way to investigate this possible new role for laser therapy in the management of primary open angle glaucoma, and preliminary results are encouraging. ${ }^{81112}$

The study was supported by the locally organised research scheme, GMC.

\section{References}

1 Krasnov MM. Laseropuncture of the anterior chamber angle in glaucoma. Am J Ophthalmol 1973; 75: 674-8.

2 Gasterland D, Kupfer C. Experimental glaucoma in rhesus monkeys. Invest Ophthalmol Vis Sci 1974; 13: 455-7.

3 Wise JB, Witter SL. Argon laser therapy for open angle glaucoma: a pilot study. Arch Ophthalmol 1979; 97: 319-22.
4 Wise JB. Long term control of adult open angle glaucoma by argon laser trabeculoplasty: Ophthalmology (Rochester) 1981; 88: 197-202.

5 Schwartz AL, Whitton ME, Bleiman B, Martin D. Argon laser trabecular surgery in uncontrolled phakic open angle glaucoma. Ophthalmology (Rochester) 1981; 88: 203-12.

6 Pohjanpelto P. Argon laser treatment of the anterior chamber angle for increased intraocular pressure. Acta Ophthalmol (Kbh) 1981; 59: 211-20.

7 Wilensky JT, Jampol LM. Laser therapy for open angle glaucoma. Ophthalmology (Rochester) 1981; 88: 213-7.

8 Migdal C, Hitchings RA. Primary therapy for chronic simple glaucoma. The role of argon laser trabeculoplasty. Trans Ophthalmol Soc UK 1985; 104: 62-6.

9 Weinreb RN, Ruderman JM, Juster R, Zweig KO. Immediate intraocular pressure response to argon laser trabeculoplasty. Am J Ophthalmol 1983; 95: 279-86.

10 Pei J, Dueker DK, Grant WM. Response of trabecular meshwork to heating. ARVO Abstract 1983; $24: 88$.

11 Rosenthal AR, Chaudhuri PR, Chiapella AP. Laser trabeculoplasty primary treatment in open angle glaucoma: a preliminary report. Arch Ophthalmol 1984; 102: 699-701.

12 Thomas JV, El-Mofty A, Hamdy EE, Simmons RJ. Argon laser trabeculoplasty as initial therapy for glaucoma. Arch Ophthalmol 1984; 102: 702-3.

Accepted for publication 1 May 1986. 